Original Research Article

\title{
An observational cross-sectional study to determine the effect of telmisartan on reducing microalbuminuria in diabetic hypertensive patients in tertiary care teaching hospital, Central India
}

\author{
Santenna Chenchula ${ }^{1 *}$, Rupesh Gupta ${ }^{2}$, Balakrishnan S. ${ }^{1}$, Akash Vishwe ${ }^{1}$, \\ Pushparaj Gour $^{1}$, Sunil Kumar ${ }^{1}$
}

${ }^{1}$ Department of Pharmacology,

${ }^{2}$ Department of General

Medicine, AIIMS, Bhopal,

Madhya Pradesh, India

Received: 31 May 2017

Revised: 02 July 2017

Accepted: 05 July 2017

*Correspondence to:

Dr. Santenna Chenchula,

Email: csanten7@gmail.com

Copyright: () the author(s), publisher and licensee Medip Academy. This is an openaccess article distributed under the terms of the Creative Commons Attribution NonCommercial License, which permits unrestricted noncommercial use, distribution, and reproduction in any medium, provided the original work is properly cited.

\begin{abstract}
Background: There are many groups of drugs to decrease microalbuminuria like angiotensin converting enzyme inhibitors (ACEI), angiotensin receptor blockers (ARBs), calcium channel blockers and direct vasodilators. Among these, ACEI and ARBs are commonly used for this purpose. If side effects occur, ACEI are replaced with ARBs. Many ARBs have been studied for their effect on reducing microalbuminuria, but data on telmisartan with its additional unique properties are scarce in Indian population.

Methods: This cross sectional observational study was carried out in a tertiary care centre. We first measured base line urine albumin levels in included patients, 3 months after treatment with telmisartan using 'hemocue urine albumin analyser'. We collected and compared both baseline and after treatment data of microalbuminuria and analysed in descriptive statistics.

Results: A total of 110 patients participated in this study; out of which 10 patients were excluded from the study because they were not available for follow up. As compared to baseline, urine albumin level decreased by $30.42 \%$ after 12 weeks treatment with telmisartan $(\mathrm{P}<0.001)$.

Conclusions: Microalbuminuria is one of the leading cause of end stage renal disease and coronary heart diseases in diabetic hypertensive patients. Drugs like ACE inhibitors, Angiotensin receptor blockers, Calcium channel blockers and direct vasodilators are used to prevent these complications. In this present study, we concluded that telmisartan decreases urine albumin excretion around $30.42 \%$ from baseline after 12 weeks of treatment.
\end{abstract}

Keywords: Diabetic nephropathy, Microalbuminuria, Telmisartan

\section{INTRODUCTION}

Nephropathy is a frequent complication of diabetes, the most common cause of kidney failure in the western world, and results in decreased life expectancy. Diabetes mellitus (DM) is a metabolic disorder with different causes, characterized by hyperglycaemia resulting from defects in insulin secretion and / or action. In year 2000171 million cases of DM worldwide were estimated and that number is expected to increase to 366 million cases in 2030 . $^{1}$ Microalbuminuria is a subclinical increase in urinary albumin excretion. By definition it defined as an albumin excretion rate of 20 to 200 milligram/Litre in the first morning sample, $20-200 \mu \mathrm{g} / \mathrm{min}$ in a timed overnight or 24 hour sample on at least 2 of 3 occasions within a period of 6 months (or) an albumin to creatinine ratio $(\mathrm{mg} / \mathrm{mmol})$ of 2.5 to 25 in males and 3.5 to 35 in females. ${ }^{2}$ Microalbuminuria is an important clinical finding because it is not only associated with an increased risk of progression to proteinuria (macroalbuminuria) and renal failure, but also increase risk for cardiovascular events. In patients who progress to nephropathy, microalbuminuria 
usually precedes macroalbuminuria by an interval of 5 to 10 years. ${ }^{3}$ The increasing prevalence of DM has led to a growing number of chronic complications including diabetic nephropathy (DN). Approximately 30\% of patients with either type 1 or type 2 DM develop DN. DN is the single most common cause of end stage renal disease (ESRD) in adults. The life time risk of developing DN with progression to ESRD is roughly same in type 1 and type 2 DM. The presence of DN indicates a marked increase in patient morbidity and premature mortality, and significantly impacts the cost of care. ESRD in those with Diabetes remains a significant predictor for increase in cardiovascular risk and mortality. ${ }^{4}$

Diabetic nephropathy is characterized by a group of diabetic pathophysiological changes which begin with glomerular hyperfiltration and renal hypertrophy, and then progress to proteinuria and glomerular filtration rate reduction. As the molecular mechanisms leading to ESRD in DN are still unknown, treatment of DN becomes complex and the therapeutic goal is difficult to achieve.,

The renin angiotensin system plays a predominant role in the renal disease evolution, not only by inducing changes in arterial pressure, glomerular physiology, but also by increasing oxidative stress through production of superoxide anion $\left(\mathrm{O}_{2}{ }^{-}\right)$is considered to be a major cause of vascular injury in diabetes which leads to microalbuminuria. An excess of the superoxide anion causes vascular injury by the formation of cytotoxic secondary reactive oxygen species i.e. peroxynitrite (ONOO-) and hydroxyl radicals ( $\left.{ }^{\circ} \mathrm{OH}\right){ }^{7}$ Uncontrolled hypertension also contributes to increases in proteinuria, and blood pressure control is associated with reduced urinary protein excretion and slowed decline in renal function. ${ }^{8}$ Achievement of a target blood pressure, that is, $<140 / 90 \mathrm{~mm} \mathrm{Hg}$ in patients with proteinuria, using a blocker of the renin-angiotensin system as part of the regimen, is recommended by current guidelines. ${ }^{9-11}$

Telmisartan is one of the angiotensin receptor blockers. Moreover, it acts as a partial agonist of peroxisome proliferator-activated receptor $\gamma$ (PPAR $\gamma$ ). ${ }^{12-14}$ Recent evidence shows that telmisartan provides renal benefit at all stages of the renal pathology in patients with type 2 DM. ${ }^{15}$ It improves endothelial function in patients with normoalbuminuria and it delays the progression to nephropathy in patients with microalbuminuria.

In a recent trial it was shown that the effect of telmisartan on protein excretion in DN appears to be better than losartan. ${ }^{16}$ More vascular protective effects of telmisartan than losartan were associated with greater antiinflammatory effects of telmisartan, as shown by attenuation of vascular nuclear factor kappa B (NFkB) activation and tumor necrosis factor $\alpha$ (TNF- $\alpha) \cdot{ }^{17}$ In the ONTARGET study, telmisartan provided similar cardiovascular protection in comparison to ramipril in patients with DM. ${ }^{18}$

\section{METHODS}

\section{Inclusion criteria}

Inclusion criteria for study population:

Male or female subjects, 21- 80 years old who also fulfil following criteria:

- Type II diabetes with Haemoglobin A1c concentration ( $\mathrm{Hb} \mathrm{A} 1 \mathrm{c})<10 \%$

- Systolic and/or diastolic blood pressure more than 140/90mm $\mathrm{Hg}$ and/or receiving an antihypertensive(s) (excluding other Angiotensin receptor blockers, angiotensin-converting enzyme inhibitors, calcium channel inhibitors and direct vasodilators).

- Who are willing to give consent.

\section{Exclusion criteria}

- Women who are either nursing, pregnant, or of childbearing age not using effective contraception.

- $\quad$ Subjects with systolic BP $\geq 170 \mathrm{mmHg}$ and or diastolic $\mathrm{BP} \geq 110 \mathrm{mmHg}$.

- Known hypersensitivity to Telmisartan or ACE inhibitors or to any component of the formulation.

- Renal dysfunction due to other than diabetes.

This cross sectional observational study was carried out in a tertiary care centre. We first measured base line urine albumin protein level in patients by taking their morning urine samples 19. We sent patients' urine samples to our hospital pathology laboratory to measure albumin level where 'hemocue urine albumin analyzer' was used to measure urine albumin. Three months after treatment with telmisartan, we again measured patients albumin urine. The results were shown in $\mathrm{mg} / \mathrm{ml}$. We collected and compared both baseline and after treatment data of microalbuminuria and analysed using descriptive statistics.

The study protocols were approved by the institutional human ethics committee of AIIMS, Bhopal. Written informed consent was obtained from all participants and guidelines of good clinical practice were followed.

\section{Statistical analysis}

Data was presented as Mean \pm SEM. Statistical analysis was performed using graph pad (Graph Pad, San Diego, CA, USA) prism software. Difference in albumin levels before and after 12 weeks treatment with telmisartan was statistically analyzed by paired t test (student $t$ test). A value of $\mathrm{P} \leq 0.005$ was taken as significant.

\section{RESULTS}

Out of 110 patients 10 patients were not available for follow up. Among remaining 100 patients more than $30 \%$ 
reduction in urine albumin excretion was seen in about 90 patients. The mean urine albumin $(\mathrm{mg} / \mathrm{l})$ in the baseline pre-treatment group was 53.05 and 12 weeks after treatment with telmisartan it was around 22.63. The mean difference observed was 30.42, and it was statistically significant $(\mathrm{P} \leq 0.001)$. We plotted a standard error bar graph diagram by taking urine albumin $(\mathrm{mg} / \mathrm{l})$ on $\mathrm{X}$ axis and rate of urine albumin reduction on $\mathrm{Y}$-axis with study results Mean and Standard error of mean (S.E.M). The graph is shown in Figure 1. The graph will give complete understanding of how much is the change with 12 weeks telmisartan therapy. The results of our study showed that in diabetic hypertensive patients telmisartan therapy has good effectiveness in reducing microalbuminuria and its progression to diabetic nephropathy.

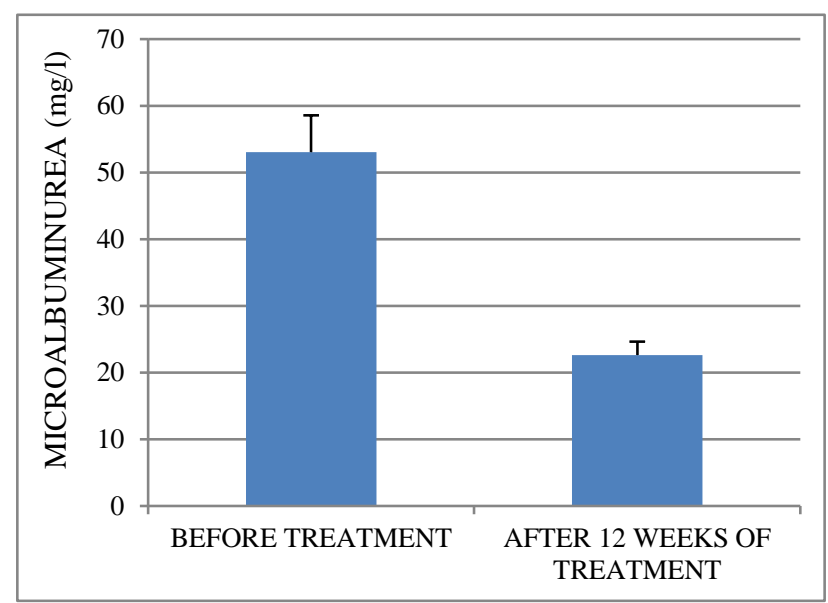

Urine albumin $(\mathrm{mg} / \mathrm{ml})$ excretion (Mean \pm Standard error of mean (S.E.M)) before and after 12 weeks of treatment with telmisartan. Urine albumin excretion was significantly lower after 12 weeks of treatment with telmisartan $(p \leq 0.05)$. Error bars represent standard error $(n=100)$.

\section{Figure 1: Effect of telmisartan on urine albune excretion before and after 12 weeks of telmisartan therapy.}

The results show complete understanding of how much change is with 12 weeks after telmisartan therapy. The results of our study in central India have shown that in patients with hypertension and diabetic microalbuminuria, telmisartan therapy has reduced its progression to diabetic nephropathy from microalbuminuria by its Renoprotective effects.

\section{DISCUSSION}

During the last decades, several studies have shown that raised urinary albumin excretion that is below the level of clinical albuminuria so called micro albuminuria strongly anticipates the development of diabetic nephropathy in both type 1 and type 2 diabetes. In the most cases with type 1diabetes it appears 5 years or more after the onset of diabetes, but in type 2 diabetes the period between the onset of diabetes and the development of microalbuminuria is less clear since the diagnosis of NIDDM is often delayed.
Nephropathy is a major cause of illness and death in diabetes. Indeed, the excess mortality of diabetes occurs mainly in diabetic nephropathy and results in not only from end stage renal disease (ESRD) but also from cardiovascular disease, with the latter being particularly common in type 2 diabetic patients. Diabetic nephropathy is the single most common cause of ESRD in Europe, Japan and the United States with diabetic patients accounting for $25 \%$ to $45 \%$ of all patients enrolled in ESRD programs. ${ }^{20-22}$

Microalbuminuria is primarily a consequence of glomerular damage. Some tubular functions are also altered in diabetes, but B2-microglobulin excretion (a sensitive index of proximal tubular reabsorptive capacity) is usually normal in microalbuminuric patients (but not in those with advanced renal failure). Loss of electrical charge and especially disruption of the size-selectivity properties of the glomerular filter occur in diabetic renal disease. These may result from abnormal synthesis of heparin sulphate, the main glycosaminoglycans component of the basement membrane which normally plays a role in the maintenance of anionic sites and pore size.

Intraglomerular hypertension due to deregulation of glomerular vessels has also been demonstrated in experimental studies and is associated with the observed increase in glomerular hyperfiltration. This hemodynamic abnormality is compounded further by systemic hypertension which is common in diabetes (especially NIDD). Although the existence and severity of hypertension are potent determinants of the prognosis of diabetes with microalbuminuria it usually appears after, rather than before or simultaneously with elevated albumin excretion. Angiotensin II has been shown to promote superoxide generation through NADPH oxidase activation, independently of its systemic vasoconstriction ability. Oxidative stress induced by superoxide anion $\left(\mathrm{O}_{2}{ }^{-}\right)$excessive formation is considered a major cause of vascular injury due to diabetes which leads to microalbuminuria. An excess of the superoxide anion causes vascular injury by the formation of cytotoxic secondary reactive oxygen species i.e. peroxynitrite (ONOO-) and hydroxyl radicals $\left({ }^{\circ} \mathrm{OH}\right)$. Experimental studies have shown that excessive superoxide is produced in human aortic endothelial cells by prolonged exposure to high glucose, and in mouse kidney glomeruli by chronic hyperglycemia. ${ }^{23,24}$ Exposure of structural and circulating proteins to high glucose levels increases the rate of their non-enzymatic glycosylation, and this may contribute to the alteration in the barrier properties of the glomerular basement membrane. Isolated micro vessels preferentially take up glycosylated albumin by endocytosis, and glycosylation of endothelial components further enhances this take-up. Moreover, glycosylated proteins, including albumin, have been shown to undergo preferential transport across the glomerular membrane. 
Telmisartan therapy has reduced its progression to diabetic nephropathy from microalbuminuria by its Renoprotective effects. It decreased around $35 \%$ from base line. Even blood pressure levels also came to controlled levels as it is an effective anti hypertensive drug. Among 100 patients around 90 patients were shown good response in their proteinuria levels by their reduced albumin levels in urine. The Mean urinary albumin in $\mathrm{mg} / \mathrm{l}$ in the baseline pre-treatment group was 53.05 and 22.63 after 3 months. The mean difference observed between two groups was 30.42 , and it was statistically significant $(\mathrm{P} \leq 0.001)$.

However, the mechanism underlying this Reno-protective effect afforded by telmisartan involves different mechanisms. Recent experimental studies have shown that telmisartan attenuates oxidative stress by down regulating NADPH oxidase, a major superoxide-producing enzyme. $^{25}$

And another study has shown that telmisartan treatment enhances serum Superoxide dismutase (SOD) activity and systemically reduces oxidative and nitrosative stress in patients with microalbuminuric patients. The increase in serum SOD activity by telmisartan treatment showed a correlation with the reduction of albuminuria in microalbuminuria patients.

Therefore, blockade of the angiotensin II signaling pathway via AT1 receptors is expected to reduce the superoxide - induced oxidative stress. Although all ARBs may share the anti-oxidative effects to some extent, there seems to be a difference. It is thought that telmisartan show its action through its strong binding affinity to AT1 receptors, the longest plasma half-life and the highest lipophilicity of currently available ARBs. Furthermore, the action of telmisartan as a partial agonist for peroxisome proliferator-activated receptor- $\gamma$ probably contributes to inhibition of NADPH oxidase. ${ }^{12-14}$

Nitric oxide (NO) has an important role in maintaining renal vascular endothelial function involved in the regulation of urinary albumin excretion. A recent clinical study reported that blood NO levels were decreased in type 2 diabetic patients with overt diabetic nephropathy compared with non-diabetic control subjects. Consistent with this study another clinical study showed increased NO levels with telmisartan and improvement of vascular endothelial function after telmisartan treatment in type 2 diabetic patients by measuring flow-mediated vasodilatation.

Thus, the increase in circulating NO following the reduction of hyperglycemia-induced oxidative stress by telmisartan treatment is thought to contribute to Reno protection.

\section{ACKNOWLEDGEMENTS}

Authors would like to thank the Department of Pathology, AIIMS, Bhopal and other staff in Medicine Department.
Funding: Funding sources from Department of pharmacology, AIIMS, Bhopal

Conflict of interest: None declared

Ethical approval: The study was approved by the Institutional Ethics Committee (IHEC-LOP/2015/IM0073)

\section{REFERENCES}

1. US Renal Data System. USRDS 2006 Annual Data Report: Atlas of End-Stage Renal Diseases in the United States. 2007 National Institutes of Health, National Institutes of Diabetes, Digestive Diseases and Kidney Diseases www.usrds.org last accessed 2/1/08.

2. Rowe DJ, Dawnay A, Watts GF. Microalbuminuria in diabetes mellitus: review and recommendations for the measurement of albumin in urine. Ann 1990 Jul;27:297-312.

3. Hillege HL, Fidler V, Diercks GF. Urinary albumin excretion predicts cardiovascular and non cardiovascular mortality in general population. Circulation. 2002;106:1777-82.

4. Bakris G. Clinical trials report. Proteinuria and blood pressure reduction: are they of equal importance to preserve kidney function? CurrHypertens Rep. 2005; 7:357-8.

5. Lea J, Greene T, Hebert L, Lipkowitz M, Massry S, Middleton $\mathrm{J}$, et al. The relationship between magnitude of proteinuria reduction and risk of endstage renal disease: results of the African American study of kidney disease and hypertension. Archives of internal medicine. 2005 Apr 25;165(8):947-53.

6. De Zeeuw D, Remuzzi G, Parving HH, Keane WF, Zhang Z, Shahinfar S, et al. Proteinuria, a target for renoprotection in patients with type 2 diabetic nephropathy: lessons from RENAAL. Kidney international. 2004 Jun 30;65(6):2309-20.

7. Evans JL, Goldfine ID, Maddux BA, Grodsky GM. Oxidative stress and stress-activated signaling pathways: a unifying hypothesis of type 2 diabetes. Endocr Rev. 2002;23:599-622.

8. Sarafidis PA, Khosla N, Bakris GL. Antihypertensive therapy in the presence of proteinuria. Am J Kidney Dis. 2007;49:12-26.

9. Bakris GL, Williams M, Dworkin L, Elliott WJ, Epstein M, Toto R, et al. Preserving renal function in adults with hypertension and diabetes: a consensus approach. American journal of kidney diseases. 2000 Sep 30;36(3):646-61.

10. Chobanian AV, Bakris GL, Black HR, Cushman WC, Green LA, Izzo JL, et al. Seventh report of the joint national committee on prevention, detection, evaluation, and treatment of high blood pressure. hypertension. 2003 Dec 1;42(6):1206-52.

11. Mancia G, De Backer G, Dominiczak A, Cifkova R, Fagard R, Germano G, et al. 2007 Guidelines for the management of arterial hypertension: The Task Force for the Management of Arterial Hypertension of the European Society of Hypertension (ESH) and of the European Society of Cardiology (ESC). European Heart Journal. 2007 Jun 1;28(12):1462-536. 
12. Benson SC, Pershadsingh HA, Ho CI, Chittiboyina A, Desai P, Pravenec $M$, et al. Identification of telmisartan as a unique angiotensin II receptor antagonist with selective PPAR gamma-modulating activity. Hypertension. 2004;43:993-1002.

13. Janke J, Schupp M, Engeli S, Gorzelniak K, Boschmann M, Sauma L, et al. Angiotensin type 1 receptor antagonists induce human in-vitro adipogenesis through peroxisome proliferatoractivated receptor gamma Activation. J Hypertens. 2006;24:1809-16

14. Schupp M, Janke J, Clasen R, Unger T, Kintscher U. Angiotensin type 1 receptor blockers induce peroxisome proliferator-activated receptor-gamma activity. Circulation. 2004;109:2054-7.

15. Burnier M. Angiotensin II type 1 receptor blockers. Circulation. 2001;103:904-12.

16. Bakris G, Burgess E, Weir M, Davidai G, Koval S. Telmisartan is more effective than losartan in reducing proteinuria in patients with diabetic nephropathy. Kidney Int. 2008;74:364-9.

17. Toyama K, Nakamura T, Kataoka K, Yasuda O, Fukuda M, Tokutomi Y, et al. Telmisartan protects against diabetic vascular complications in a mouse model of obesity and type 2 diabetes, partially through peroxisome proliferator activated receptor- $\gamma$ dependent activity. Biochemical and biophysical research communications. $2011 \mathrm{Jul}$ 8;410(3):508-13.

18. The ONTARGET Investigators $\mathrm{N}$ Engl $\mathrm{J}$ Med. 2008;358:1547-59.

19. Leon G. Fine and Salehmoghaddam. Clinical Methods: The History, Physical, and Laboratory Examinations. $3^{\text {rd }}$ Edition.
20. Borch-Johnsen K. the prognosis of insulin-dependent diabetes mellitus.an epidemiological approach. Dan med bull. 1989;39:336-49.

21. Ballard DJ, Humphrey LL, Melton LJ, Frohnert PP, Chu CP, O'Fallon WM, et al. Epidemiology of persistent proteinuria in type II diabetes mellitus: population-based study in Rochester, Minnesota. Diabetes. 1988 Apr 1;37(4):405-12.

22. Gall MA, Borch-Johnsen K, Hougaard P, Nielsen FS, Parving HH. Albuminuria and poor glycemic control predict mortality in NIDDM. Diabetes. 1995 Nov 1;44(11):1303-9.

23. Cosentino F, Hishikawa K, Katusic ZS, Luscher TF. High glucose increases nitric oxide synthase expression and superoxide anion generation in human aortic endothelial cells. Circulation. 1997;96:25-8.

24. Fujita H, Fujishima H, Chida S, Takahashi K, Qi Z, Kanetsuna Y, et al. Reduction of renal superoxide dismutase in progressive diabetic nephropathy.J Am Soc Nephrol. 2009;20:1303-13.

25. Sugiyama H, Kobayashi M, Wang DH, Sunami R, Maeshima Y, Yamasaki Y, et al. Telmisartan inhibits both oxidative stress and renal fibrosis after unilateral ureteral obstruction in acatalasemic mice. Nephrol Dial Transplant. 2005;20:2670-80.

Cite this article as: Chenchula $S$, Gupta $R$,

Balakrishnan S, Vishwe A, Gour P, Kumar S. An observational cross-sectional study to determine the effect of telmisartan on reducing microalbuminuria in diabetic hypertensive patients in tertiary care teaching hospital, Central India. Int J Basic Clin Pharmacol 2017;6:2082-6. 